\title{
Correlation between Particulate Matter and Microbial Counts in Hospital Operating Rooms
}

\section{${ }^{1}$ Keng Yinn Wong, ${ }^{2}$ Haslinda Mohamed Kamar, ${ }^{3}$ Nazri Kamsah, ${ }^{4}$ Fazila Mohd Zawawi, ${ }^{5}$ Huiyi Tan, ${ }^{6}$ Md. Nor Musa, ${ }^{7}$ Muhd Suhaimi Deris}

1,2,3,4,7 Universiti Teknologi Malaysia, Faculty of Mechanical Engineering, 81310 Skudai, Johor, Malaysia,

${ }^{5}$ Universiti Teknologi Malaysia, Faculty of Biosciences \& Medical Engineering, 81310 Skudai, Johor, Malaysia,

${ }^{6}$ Universiti Teknologi Malaysia, UTM Ocean Thermal Energy Centre, 57000 Kuala Lumpur, Malaysia.

Correspondence Author: Haslinda Mohamed Kamar, Universiti Teknologi Malaysia, Faculty of Mechanical Engineering, 81310 Skudai, Johor, Malaysia Tel.: +(6)07-5534748

E-mail: haslinda@mail.fkm.utm.my

Received date: 23 July 2018, Accepted date: 10 October 2018, Online date: 15 October 2018

Copyright: (C) 2018 Keng Yinn Wong et al., This is an open-access article distributed under the terms of the Creative Commons Attribution License, which permits unrestricted use, distribution, and reproduction in any medium, provided the original author and source are credited.

\begin{abstract}
This article presents the findings of an experimental investigation for evaluating correlative relations between particulate matter and microbial concentrations in seven hospital operating rooms. All of the rooms have a positive pressure differential of more than $7 \mathrm{~Pa}$ to the adjacent zones. The operating parameters such as air temperature, room pressure, relative humidity and supply air velocity are in compliance with the ISO Class 7 specifications. The PMS Lasair III 310C particle counter was used to measure four different sizes of particulate matter (PM); namely, PM 1, PM 5, PM 10 and PM 25. A MAS-100ECO microbial air sampler was used to measure the microbial counts. The results confirmed that PM 1 and PM 5 do not have an apparent positive correlation with microbial. The amount of PM 1 has no mutual relationship to microbial level. However, on average, PM 5, PM 10 and PM 25 give small correlation percentages to microbial concentration, namely by $5 \%, 10 \%$ and 20 $\%$, respectively.
\end{abstract}

Key words: Operating rooms, particulate matters, microbes, air sampling

\section{INTRODUCTION}

Surgical site infection (SSI) is a hospital-acquired infection (HAI) that possibly incurs after surgical procedures, in which can be especially severe in orthopaedic surgery [1]. A study revealed that SSI was the third most frequently reported HAI [2]. Recently, Anderson [3] and Mangram et al. [2] reported that SSI contributes to $10 \%$ to $11 \%$ and $14 \%$ to $16 \%$ of HAI in the USA and Georgia, respectively. Anderson et al. [4]described that SSI caused an increment of two to eleven times in mortality rate, the length of hospitalisation, treatment-associated risks, and patient dissatisfaction. In 2012, Awad [5] claimed that SSI contributed to $3 \%$ of a mortality rate. Also, SSI could increase a patient's hospital stay by approximately ten days [2]. The treatment costs of SSI were estimated to be less than $\$ 400$ to more than $\$ 30,000$, depending on the type of infection [6].

Many factors lead to SSI [1]. They depend on microbial contamination of the air, the type of surgery, and the behaviour of staff in the operating room [1, 7 , 8]. The proportion of contaminated wounds in cardiac surgery can be as high as $89 \%$. Air in the operating room is a conduit for microbial entry to an open clean surgical wound [7]. The number of viable airborne bacteria in the operating room is highly related to the infection risk to surgical patients [6]. SSI can be prevented by adhering to rigorous environmental control protocols. Napoli et al. [8]concluded that the infection rates are relating to the concentrations of airborne particle settled on the wound, and they implied monitoring the particle level in the operating room is very significant.

Various types of microorganisms such as Staphylococcus aureus, Sphingomonas paucimobilis, Pseudomonas aeruginosa, Stenotrophomonas maltophilia, Clostridium difficile, Legionella spp. and Pseudomonas aeruginosa are commonly existing in healthcare facilities. They are the primary cause of HAI [9]. Staphylococcus aureus and Coagulase-negative staphylococcus (CoNS) are the main bacterial species found in the operating room, and they are the most common cause of SSI [10, 11]. Humphreys et al. [12] stated that $39 \%$ to $44 \%$ of SSI cases are due to Staphylococcus aureus, whereas Streptococcus spp., Enterococcus spp., and Aerobic gram-negative bacilli are less likely to be existent in the operating room. Mansson et al. reported that the percentages of these species found in the operating room were only $6 \%, 2 \%$ and $6 \%$, respectively. SSI cannot be treated by commonly used antibiotics due to the increasing resistance of Staphylococcus aureus to conventional drugs, in which it is known as Methicillin-resistant Staphylococcus aureus (MRSA). MRSA fits to survive under dry conditions for a longer period, especially in a less cleaned area [9]. According to Ismail et al. [9], from all types of Staphylococcus aureus, 9.3 \% were identified as MRSA. It comprised $4.2 \%, 3.1 \%$ and $2.0 \%$ in the adult intensive care units (ICU), Nursery ICU and operating rooms, respectively.

Several studies suggested that the microbial level in operating rooms can be evaluated by assessing the amount of particulate matters (PMs). Chow and Wang [13] proposed that only two types of PM have a significant relation to the microbial, they are PM 5 to PM 10. Wagner et al. [14] described the amount of microbial is a correlative of the quantity of PM 10. While Romano et al. [15] suggested both PM 0.5 to PM 10 possess a significant effect on the number of microbial. To date, however, no current evidence has established the precise size of PM that has a significant effect on the microbial [7]. This article presents the findings of an experimental study conducted in seven operating rooms for evaluating correlative relations between PM concentrations on the microbial. The aim of this study is to establish a relationship between the amount of PM on the microbial levels.

Methodology:

This study was carried out at seven operating rooms of three different private hospitals, located in Selangor, Malaysia. These operating rooms have been the 
subject of an air change rate study [16]. In each operating room air samples were taken according to the suggested ISO norm, namely, at rest condition (during the hours following midnight) by a standardised procedure. The particulate matter and microbial measurements were conducted on the same day. However, both tests were not carried out concurrently. The measurements have been performed over a three-month period between July 2015 and November 2015.

\section{Description of the operating rooms:}

The operating rooms in this study are mainly used for general and orthopaedic surgery [16]. They are built according to ISO Class 7 cleanroom standards. The size of the operating rooms ranges from $91 \mathrm{~m}^{3}$ to $143 \mathrm{~m}^{3}$ (mean volume: $119 \mathrm{~m}^{3}, \mathrm{SD}: \pm 18.3 \mathrm{~m}^{3}$ ). All the operating rooms utilise a similar type of ventilation. The supply air diffusers are mounted on the ceilings and supply a unidirectional flow of air to the room. Each diffuser is equipped with a high-efficiency particulate air (HEPA) filter. The HEPA filter is designed to trap $99.97 \%$ of particles as small as PM 0.3 [16, 17]. A recent study claimed that the use of HEPA system is capable of eliminating a pulmonary aspergillosis fungus, which is harmful to immune-compromised patients [8]. Each operating room is equipped with two surgical lamps, six supply air diffusers and four exhaust grilles. Table 1 gives the description of the operating room.

Table 1: Description of the operating room.

\begin{tabular}{|c|c|}
\hline Operating systems & Description \\
\hline Standard & ISO Class 7 \\
\hline Room Size & $91 \mathrm{~m}^{3}$ to $143 \mathrm{~m}^{3}$ \\
\hline Exhaust Grilles & $0.22 \mathrm{~m}(\mathrm{~W}) \times 0.46 \mathrm{~m}(\mathrm{H})$ \\
\hline Air-Supply Diffusers & $1.2 \mathrm{~m}(\mathrm{~W}) \times 0.6 \mathrm{~m}(\mathrm{~L})$ \\
\hline Surgical Lamp & $0.58 \mathrm{~m}(\mathrm{D})$ \\
\hline
\end{tabular}

D represents diameter, $H$ represent height, $L$ represents length and $W$ represents width

\section{Instrumentation set-up:}

The measurements of particulate matter and microbial concentrations were carried out at a $1.1 \mathrm{~m}$-height above floor level. The sampling set-up was similar to the studies done by Kamar et al. [17] and Wong et al. [16]. A tripod was used to position the instrument firmly at the sampling grids. A total of six sampling grids were assigned for each room, as shown in Figure 1. Measurements were conducted at the centre of each sampling grid. No surgical procedure was taking place inside the operating rooms for at least 12 hours before the measurements were performed[16].
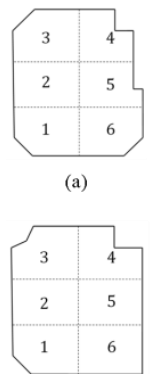

(d)

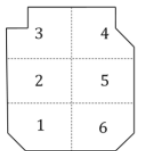

(b)

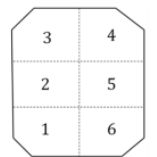

(e)

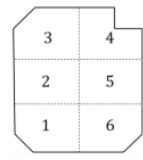

(c)

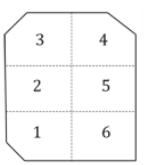

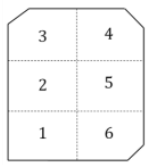

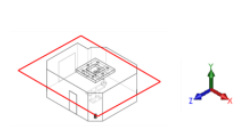

(g)

Fig. 1: Sampling grids for (a) OR 1, (b) OR 2, (c) OR3, (d) OR 4, (e) OR 5, (f) OR 6 and (g) OR 7.

Particulate matter measurements:

PM measurements were performed using a PMS Lasair III 310C particle counter with the efficiency of $50 \% \pm 20 \%$. Samples were taken at one-minute intervals with a flow rate of $28.3 \mathrm{~L} / \mathrm{min}$ [7]. Four different sizes of particulate matter were measured, namely, PM 1, PM 5, PM 10, and PM 25. The concentrations of measured particulate matter were expressed in particles $/ \mathrm{m}^{3}$.

Microbial measurements:

Microbial measurements were performed using a MAS-100ECO air sampler at a flow rate of $100 \mathrm{~L} / \mathrm{min}$. A Petri plate with Tryptic Soy Agar (TSA) was used to obtain the total bacteria intensities while Saboraud Dextrose Agar (SDA) was used to determine the total amount of fungal. After completing the measurements, the samples were analysed at a separate location, usually at a microbiology facility. Both TSA plates and SDA were incubated at specified temperatures for specific time spans, i.e. at $35^{\circ} \mathrm{C}$ for a two-day time span, and $25^{\circ} \mathrm{C}$ for a five-day time span, respectively. The total amount of microbial is the sum of the bacteria and fungi quantities (measured in $\mathrm{cfu} / \mathrm{m}^{3}$ ).

Correlation percentage calculation:

Equation (1) expresses a correlation percentage for testing the influence of PM to the microbial quantities, where $n$ denotes the number of operating rooms.

Correlation percentage $=\frac{\left(\frac{\text { Microbial counts }}{P M \text { counts }}\right)_{1}+\left(\frac{\text { Microbial counts }}{P M \text { counts }}\right)_{2}+\ldots . . .+\left(\frac{\text { Microbial counts }}{P M \text { counts }}\right)_{n}}{n} \times 100 \%$

Standard deviation and standard error calculations:

Standard deviation is a measure of dispersion of the measured data. Whereas, standard error estimates the sampling fluctuation statistically. Both are formulated by Equations (2) and (3), respectively.

$$
\sigma=\sqrt{\frac{\sum_{i=1}^{n}\left(x_{i}-\ddot{x}\right)^{2}}{n}}
$$


where $\sigma$ is the standard deviation, $n$ is the number of measurements of the data, $\ddot{x}$ is the sample mean and $x_{i}$ is the measurement value.

$$
S E=\frac{\sigma}{\sqrt{n}}
$$

where $S E$ is standard error, $\sigma$ is the standard deviation and $n$ is the number of the measured data.

\section{RESULT AND DISCUSSION}

The concentrations of PM 1, PM 5, PM 10, PM 25, bacteria, and fungi are shown in Table 2. The levels of all types of PM is below the threshold values prescribed in the ISO Class 7 standard[18]. The total amount of bacteria and fungi have also met the guidelines set by the Policies and Procedures on Infection Control, i.e. less than $35 \mathrm{cfu} / \mathrm{m}^{3}[19]$.

Table 2: Average concentrations of particulate matter and microbial counts in the seven operating rooms

\begin{tabular}{|c|c|c|c|c|c|c|c|}
\hline \multirow[t]{2}{*}{ Location } & \multicolumn{4}{|c|}{ Concentration(particles $/ \mathrm{m}^{3}$ ) } & \multicolumn{3}{|c|}{ Concentration $\left(\mathrm{cfu} / \mathrm{m}^{3}\right)$} \\
\hline & PM1 & PM5 & PM10 & PM25 & Bacteria & Fungi & Total microbe \\
\hline OR 1 & 12183 & 94 & 38 & 13 & 2 & - & 2 \\
\hline OR 2 & 10288 & 171 & 84 & 33 & 5 & 4 & 9 \\
\hline OR 3 & 10170 & 112 & 53 & 29 & 7 & 1 & 8 \\
\hline OR 4 & 26756 & 230 & 125 & 41 & 5 & 2 & 7 \\
\hline OR 5 & 6898 & 224 & 121 & 38 & 4 & - & 4 \\
\hline OR 6 & 57273 & 1184 & 374 & 98 & 11 & - & 11 \\
\hline OR 7 & 7988 & 1636 & 741 & 35 & 4 & - & 4 \\
\hline ISO Standard / Policies and Procedures on Infection Control & 83200 & 2930 & N/A & N/A & 35 & 35 & N/A \\
\hline
\end{tabular}

The correlations percentage between PM sizes and the microbial levels are shown in Figure 2. The findings indicate that PM 1 does not possess any positive correlation with microbial intensities. However, PM 5, PM 10 and PM 25 show a small positive correlation with the microbial amount. On average, the correlation percentages of PM 5, PM 10 and PM 25 that correspond to microbial levels are 5\%,10\% and $20 \%$, respectively. These findings agree with the works done by Sadrizadeh et al. [20] and Wagner et al. [21]. They have also concluded that the infectious particles exist in clusters of PM 10 and above.

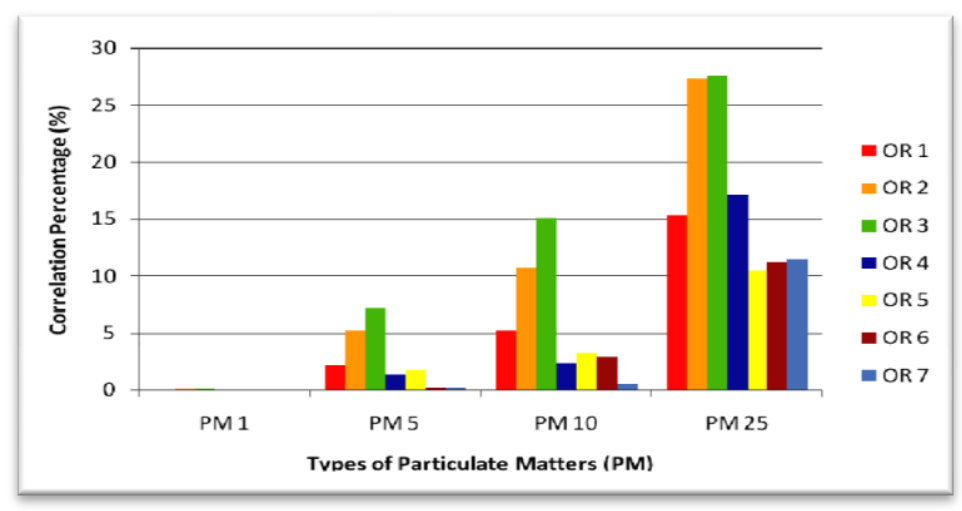

Fig. 2: Correlation percentage between microbial and PMs concentrations.

Table 3 tabulates the standard deviation and standard error of the entire measured PM. A small standard deviation indicates that the variance between the individual data and sample mean is irrelevant. Whereas, a low value of standard error shows that the sample mean is prone to the population mean.

Table 3: Standard deviation and standard error for each PM.

\begin{tabular}{|c|c|c|c|c|c|c|c|c|}
\hline \multirow{2}{*}{ Location } & \multicolumn{3}{|c|}{ Standard Deviation } & \multicolumn{4}{c|}{ Standard Error } \\
\cline { 2 - 9 } & PM 1 & PM 5 & PM 10 & PM 25 & PM 1 & PM 5 & PM 10 & PM 25 \\
\hline OR 1 & 5088 & 58 & 13 & 5 & 2133 & 24 & 26 & 2 \\
\hline OR 2 & 4820 & 165 & 28 & 8 & 1820 & 67 & 79 & 3 \\
\hline OR 3 & 3598 & 142 & 20 & 9 & 1607 & 58 & 61 & 3 \\
\hline OR 4 & 10182 & 312 & 48 & 3 & 4189 & 127 & 138 & 1 \\
\hline OR 5 & 3984 & 154 & 41 & 4 & 1277 & 77 & 49 & 1 \\
\hline OR 6 & 18354 & 551 & 127 & 16 & 6230 & 276 & 203 & 6 \\
\hline OR 7 & 3108 & 772 & 288 & 7 & 1327 & 315 & 108 & 3 \\
\hline
\end{tabular}

Conclusion:

The microbial level in operating rooms could significantly cause SSI. In this study, an experimental investigation for evaluating correlative relations between particulate matter and microbial quantities in seven hospital operating rooms have been carried out. The findings show that the amount of PM 1 has no mutual relationship to microbial level. On average, the correlation percentages of PM 5, PM 10 and PM 25 that correspond to microbial levels are $5 \%, 10 \%$ and $20 \%$, respectively.

\section{ACKNOWLEDGEMENT}

The authors would like to acknowledge the Ministry of Higher Education (MOHE), Malaysia, under the FRGS Grant with Vot No. 4F645 and Ainuddin Wahid Scholarship through the VOT No. of A.J100000.5900.06000. 


\section{REFERENCES}

[1] Cristina, M.L., A.M. Spagnolo, M. Sartini, D. Panatto, R. Gasparini, P. Orlando, G. Ottria and F. Perdelli, 2012. Can particulate air sampling predict microbial load in operating theatres for arthroplasty? PloS one., 7(12): e52809.

[2] Mangram, A.J., T.C. Horan, M.L. Pearson, L.C. Silver, W.R. Jarvis and H.I.C.P.A. Committee, 1999. Guideline for prevention of surgical site infection.American journal of infection control, 27(2): 97-134.

[3] Erichsen Andersson, A., 2013. Patient Safety in the OR-Focus on Infection Control and Prevention.

[4] Anderson, D.J., K. Podgorny, S. I.Berríos-Torres, D.W. Bratzler, E.P. Dellinger, L. Greene, A.C. Nyquist, L. Saiman, D.S. Yokoe and L.L. Maragakis, 2014. Strategies to prevent surgical site infections in acute care hospitals: 2014 update.Infection Control \& Hospital Epidemiology, 35(06): 605-627.

[5] Awad, S.S., 2012. Adherence to surgical care improvement project measures and post-operative surgical site infections. Surgical infections. 13(4): 234-237.

[6] Sadrizadeh, S., A. Tammelin, P. Ekolind and S. Holmberg, 2014. Influence of staff number and internal constellation on surgical site infection in an operating room.Particuology, 13: 42-51.

[7] Birgand, G., G. Toupet, S. Rukly, G. Antoniotti, M.N. Deschamps, D. Lepelletier, C. Pornet, J.B. Stern, Y.M. Vandamme and N. Van der Mee-Marquet, 2015. Air contamination for predicting wound contamination in clean surgery: A large multicenter study.American journal of infection control, 43(5): 516-521.

[8] Napoli, C., V. Marcotrigiano and M.T. Montagna, 2012. Air sampling procedures to evaluate microbial contamination: a comparison between active and passive methods in operating theatres.BMC Public Health, 12(1): 594.

[9] Saadoun, I., Z.W. Jaradat, I.A. Al Tayyar, Z. El Nasser and Q. Ababneh, 2014. Airborne methicillin-resistant Staphylococcus aureus in the indoor environment of King Abdullah University Hospital, Jordan.Indoor and Built Environment. $1420326 X 14526604$.

[10] Sadrizadeh, S. and S. Holmberg, 2015. Effect of a portable ultra-clean exponential airflow unit on the particle distribution in an operatng room. Particuology, 18: 170-178.

[11] Månsson, E., B. Hellmark, M. Sundqvist and B. Söderquist, 2015. Sequence types of Staphylococcus epidermidis associated with prosthetic joint infections are not present in the laminar airflow during prosthetic joint surgery.Apmis, 123(7): 589-595.

[12] Humphreys, H., J. Coia, A. Stacey, M. Thomas, A.M. Belli, P. Hoffman, P. Jenks and C. Mackintosh, 2012. Guidelines on the facilities required for minor surgical procedures and minimal access interventions.Journal of Hospital Infection, 80(2): 103-109.

[13] Wang, J. and T.T. Chow, 2015. Influence of human movement on the transoprt airborne infectious particles in hospital.Journal of Building Performance Simulation, 8(4): 205-215.

[14] Wagner, J.A., K.J. Schreiber and R. Cohen, 2014. Improving Operating Room Contamination Control.ASHRAE Journal, 1827.

[15] Romano, F., L. Marocco, J. Gusten and C.M. Joppolo, 2015. Numerical and experimental analysis of airborne particles control in an operating theater. Building and Envionment, 89: 369-379.

[16] Wong, K.Y., H.M. Kamar, N. Kamsah, F.M. Zawawi, M.N. Musa and M.S. Deris, 2016. Effect of air-change rate on airborne particles concentration in hospital operating rooms.Jurnal Teknologi (Science \& Engineering).

[17] Kamar, H.M., N. Kamsah, K.Y. Wong, M.N. Musa and M.S. Deris, 2015. Field measurement of airborne particulate matters concentration in a hospital's operating room.Jurnal Teknologi (Science \& Engineering). 77(30): 63-67.

[18] Standard, 1999. ISO 14644-1,Cleanrooms and associated controlled environments. United Kingdom.

[19] Malaysia, M.O.H., 2010. Policies and Procedures on Infection Control. In Division, M. D. Editor.: Ministry of Health Malaysia, 1-209.

[20] Sadrizadeh, S., S. Holmberg and A. Tammelin, 2014. A numerical investigation of vertical and horizontal laminar airflow ventilation in an operating room.Building and Environment. 82: 517-525.

[21] Wagner, J.A. and K.J. Schreiber, 2014. Improving operating room contamination control.Ashrae Journal, $56(2)$ : 18. 